\title{
ANALISIS KINERJA BEA CUKAI INDONESIA YANG DIPENGARUHI OLEH BUDAYA ORGANISASI, PARTISIPASI STAKEHOLDER, TEKNOLOGI INFORMASI, DAN TRANSFER OF KNOWLEDGE
}

\author{
Aditya Dharmawan ${ }^{1}$, Susilo Toto Raharjoㄹ, Amie Kusumawardhani ${ }^{3}$ \\ ${ }^{1}$ Kementerian Keuangan Republik Indonesia \\ ${ }^{2}$ Magister Manajemen, Fakultas Ekonomika dan Bisnis, Universitas Diponegoro \\ ${ }^{3}$ Magister Manajemen, Fakultas Ekonomika dan Bisnis, Universitas Diponegoro
}

\begin{abstract}
ABSTRAK
Peningkatan kinerja organisasi publik, khususnya Bea dan Cukai (Direktorat Jederal Bea dan Cukai) di Indonesia dipengaruhi oleh beberapa faktor.Penelitian dilakukan dengan menganalisis faktor-faktor yang mempengaruhi kinerja organisasi, yaitu variabel budaya organisasi, variabel partisipasi stakeholder, variabel teknologi informasi dan variabel transfer of knowledge serta menggunakan ukuran organisasi sebagai variabel kontrol.Berangkat dari permasalahan penelitian, yaitu bagaimana meningkatkan kinerja organisasi pada instansi Direktorat Jenderal Bea dan Cukai dengan memperhatikan faktor-faktor yang mempengaruhi kinerja organisasi tersebut.

Sampel penelitian berjumlah 107 responden dengan tingkat respon 100\%.Responden pada penelitian ini adalah pegawai DJBC yang berasal dari Kantor Pengawasan dan Pelayanan Bea dan Cukai(KPPBC) dan Kantor Pelayanan Utama (KPU) Bea dan Cukai se-Indonesia dan dianggap mewakili unit kerjanya masing-masing.Alat yang digunakan untuk menganalisis adalah Structural Equation Modeling (SEM) pada program software AMOS 24.

Hasil pengolahan data menggunakan SEM untuk model teoritis telah memenuhi goodness of fit, dengan nilai Chi Square = 195.916(tanpa variabel control)/213.185(dengan variabel control), $C M I N / D F=1.037$ (tanpa variabel control)/1.035(dengan variabel control), Probability= 0.350(tanpa variabel control)/0.351(dengan variabel control), GFI $=0.863$ (tanpa variabel control)/0.860(dengan variabel control), AGFI = 0.817(tanpa variabel control) $/ 0.813$ (dengan variabel control), TLI = 0.994(tanpa variabel control)/0.993(dengan variabel control), $C F I=$ 0.995(tanpa variabel control)/0.995(dengan variabel control), $R M S E A=0.019$ (tanpa variabel control)/0.018(dengan variabel control). Dari empat hipotesis yang diuji, semua hipotesis dinyatakan diterima. Transfer of knowledge, teknologi informasi, dan partisipasi stakeholder berpengaruh signifikan terhadap kinerja organisasi pada $\alpha=5 \%$, sementara budaya organisasi berpengaruh terhadap kinerja organisasi dengan signifikansi $\alpha=10 \%$. Selain itu, ukuran organisasi sebagai variabel kontrol juga berpengaruh signifikan terhadap kinerja organisasi.
\end{abstract}

Kata Kunci: budaya organisasi, partisipasi stakeholder, teknologi informasi, transfer of knowledge, ukuran organisasi, variabel control, kinerja organisasi publik, bea cukai.

${ }^{1}$ Corresponding author, Email:

aditya.dharmawan@graduate.uwa.edu.au 


\section{PENDAHULUAN}

Setiap organisasi publik dituntut untuk dapat menjalankan fungsinya dengan baik.Namun pada prakteknya, hambatan seringkali datang dari internal organisasi (Adam dan Balfour, 2009) ataupun pihak lain, seperti legislatif (Rainey, 2010).Hal ini juga yang menimpa Direktorat Jenderal Bea dan Cukai (DJBC). Pada tahun 2005, Indonesian Corruption Watch (ICW) pernah memberitakan hasil riset dari Transparency International Indonesia (TII) bahwa Bea Cukai dianggap memiliki kinerja yang buruk (terkorup dan rendah produktivitasnya), disusul oleh Kepolisian pada posisi kedua, dan TNI pada tempat ketiga. Menindaklanjuti hal tersebut, mulai tahun 2007, Kementerian Keuangan khususnya Bea Cukai (DJBC) melakukan reformasi birokrasi dan terus melakukan perbaikan hingga sekarang.

Fenomena gap yang terjadi adalah pencapaian target penerimaan sebagai salah satu indikator kinerja utama DJBC sejak 2014 - 2016 selalu tidak mencapai target, baru pada 2017 tercapai target penerimaan. Hal ini menarik untuk diteliti apakah pencapaian kinerja organisasi initerkait dengan budaya organisasi, partisipasi stakeholder, teknologi informasi, serta transfer of knowledge yang ada dalam organisasi tersebut. Gap pada penelitian ini dijelaskan dalam Tabel 1.

\section{Tabel 1}

Gap Penelitian

\begin{tabular}{|c|c|c|c|}
\hline No & Peneliti & Hasil & Research Gap \\
\hline 1. & $\begin{array}{l}\text { Testa dan Sipe (2013), } \\
\text { Puspitasari, et.al. (2016), } \\
\text { Taylor (2014), Pangewa } \\
\text { (2015) } \\
\text { Juwita dan Adzkhiyah } \\
\text { (2017) }\end{array}$ & $\begin{array}{l}\text { Budaya organisasi } \\
\text { berpengaruh terhadap } \\
\text { kinerja organisasi } \\
\text { Budaya organisasi tidak } \\
\text { berpengaruh terhadap } \\
\text { kinerja organisasi } \\
\text { pemerintahan }\end{array}$ & $\begin{array}{l}\text { Hasil penelitian yang } \\
\text { kontradiktif }\end{array}$ \\
\hline 2. & $\begin{array}{l}\text { Yang dan Hsieh (2007), } \\
\text { William (2014), Mlaya } \\
\text { (2015), Nyandika dan } \\
\text { Ngugi (2014) }\end{array}$ & $\begin{array}{l}\text { Terdapat perbedaan } \\
\text { variable yang digunakan } \\
\text { dalam penelitian. }\end{array}$ & $\begin{array}{l}\text { Variabel yang digunakan } \\
\text { dalam penelitian ini, yaitu } \\
\text { budaya organisasi, partisipasi } \\
\text { stakeholder, teknologi } \\
\text { informasi, transfer of } \\
\text { knowledge }\end{array}$ \\
\hline 3. & $\begin{array}{l}\text { Gupta dan Govindarajan } \\
(2000) \text {, Hakanson dan } \\
\text { Nobel (2000), Bresman, } \\
\text { et.al. (2010) }\end{array}$ & $\begin{array}{l}\text { Transfer of knowledge antar } \\
\text { organisasi atau antar } \\
\text { entitas }\end{array}$ & $\begin{array}{l}\text { Transfer of knowledge internal } \\
\text { organisasi. }\end{array}$ \\
\hline 4. & $\begin{array}{l}\text { Gwardzinska (2011) } \\
\text { Amin (2008) }\end{array}$ & $\begin{array}{l}\text { Penelitian di Bea Cukai Uni } \\
\text { Eropa } \\
\text { Penelitian di Bea Cukai } \\
\text { Malaysia }\end{array}$ & $\begin{array}{l}\text { Penelitian di institusi Bea } \\
\text { Cukai Indonesia }\end{array}$ \\
\hline
\end{tabular}

\section{TELAAH PUSTAKA Kinerja Organisasi}

Kinerja organisasi merupakan tingkat keberhasilan (Keban, 2003) hasil aktivitas suatu organisasi (Prawirosentono, 2008) baik secara kualitas atau kuantitas (Mangkunegara, 2010) sesuai tanggung jawabnya. Dengan kata lain, kinerja 
organisasi adalah hasil pencapaian organisasi terhadap target yang telah ditetapkan sebelumnya.

Indikator yang digunakan untuk mengukur kinerja organisasi kepabeanan, yaitu: (a) Ketepatan waktu penyelesaian proses kepabeanan dan cukai (Bobrova, 2016; Matsuda, 2011); (b) Realisasi penerimaan bea dan cukai (Federal Board of Revenue, 2015); (c) Kepatuhan pengguna jasa (Lumanaj, 2015); (d) Kualitas pelaksanaan anggaran (Bobrova, 2016).

\section{Budaya Organisasi}

Budaya organisasi merupakan normanorma, asumsi, atau nilai-nilai dominan yang diyakini sebagai filosofi kerja dalam organisasi tersebut (Schein, 2004; Peteraf, 1993; Djokosantoso, 2003).

Indikator yang digunakan untuk menguji budaya organisasi dalam penelitian ini adalah: (a) integritas (integrity); (b) keterlibatan pegawai (involvement); (c) komunikasiefektif (communication pattern); (d) pemberian penghargaan (reward system);(e) lingkungan pengendalian internal (control); (f) pemahaman tujuan organisasi (mission).

\section{Partisipasi Stakeholder}

Stakeholder merupakan pemangku kepentingan, baik eksternal maupun internal yang berpengaruh terhadap kinerja organisasi (Yang dan Hsieh, 2007).Partisipasi stakeholder dalam penelitian ini adalah peran serta dari instansi-instansi di luar DJBC dan masyarakat pengguna jasa.Partisipasi stakeholder diukur dengan indicatorindikator sebagai berikut: (a) inisiasi (analisis kebutuhan); (b) perencanaan (menyusun tujuan); (c) implementasi (supervisi); (d) evaluasi.

\section{Teknologi Informasi}

Teknologi informasi merupakan suatu metode pengumpulan, pemrosesan, dan penyebaran informasi (Sarossa dan Zowghi, 2003). Selain itu, dapat diartikan juga sebagai suatu sistem informasi yang berbasis computer (Atkinson, 2002; O'brien dan Marakas, 2010). Indikator teknologi informasi dapat berupa: (a) ketersediaan teknologi informasi; (b) penggunaan teknologi informasi; (c) kemudahan akses terhadap informasi; (d) ketersediaan tenaga ahli teknologi informasi.

\section{Transfer of Knowledge}

Secara definisi, transfer of knowledge dapat diartikan sebagai proses pertukaran ilmu pengetahuan dari satu rganisasi ke organisasi lain (Easterby-Smith et.al. dalam Hajidimitrou, 2010; Argote dan Ingram, 2000; Wong dalam Duan et.al., 2010). Transfer of knowledgedapat diartikan juga sebagai difusi ilmu pengetahuan dalam suatu organisasi (Rosenblatt, 2011) yang digunakan sebagai dasar pengambilan keputusan (Bose, 2009) dalam penanganan masalah (Chong, 2011:503). Indikator transfer of knowledge dalam penelitian ini adalah: (a) pelatihan (training program); (b) komunikasi antar pegawai (communication); (c) kerjasama antar pegawai (team work); (d) implementasi pengetahuan pada pekerjaan (understanding).

\section{Pengembangan Hipotesis}

Penelitian terdahulu yang dilakukan Testa and Sipe (2013) menyatakan bahwa budaya organisasi mempengaruhi kinerja organisasi dalam suatu pemerintahan. Menurut Pangewa (2015), budaya organisasi mempengaruhi kinerja pemerintah daerah (Pemda Pinrang). Ketika suatu organisasi memiliki budaya organisasi yang mengutamakan integritas, 
keterlibatan pegawai (involvement), mendorong komunikasi efektif (communication pattern), konsistensi pemberian penghargaan (reward system),lingkungan pengendalian internal (control), serta mendorong pemahaman tujuan organisasi (mission)dapat meningkatkan kinerja organisasi. Dengan demikian, budaya organisasi memiliki pengaruh positif terhadap kinerja organisasi.

H1: Budaya Organisasi berpengaruh positif terhadap Kinerja Organisasi.

Chen (2017) dalam penelitiannya menyimpulkan bahwa kinerja organisasi dipengaruhi oleh partisipasi stakeholder, yang meliputi masyarakat, pimpinan lembagapemerintahan, serta pegawai pemerintahan. Namun demikian, Thomas dalam bukunya yang berjudul Public Participation in Public Decisions: New Skills and Strategies for Public Managers menyatakan bahwa partisipasi stakeholder tidak memiliki hubungan yang signifikan terhadap kinerja organisasi publik (Yang dan Hsieh, 2007).

H2: Partisipasi Stakeholder berpengaruh positif terhadap Kinerja Organisasi

Banyak peneliti yang menyimpulkan bahwa teknologi informasi data meningkatkan kinerja suatu organisasi (Chowdury, 2003; Morikawa, 2004; Dedrick et.al, 2003; Lai et.al, 2005; Ismail et.al, 2012).Lebih khusus dalam institusi kepabeanan, Gwardzinska (2011) menyimpulkan bahwa teknologi infomasi berpengaruh terhadap peningkatan kinerja institusi kepabeanan di Uni Eropa dan Malaysia (Amin, 2008).

H3: Teknologi Informasi berpengaruh positif terhadap Kinerja Organisasi.
Levine dan Prietula (2012) menyimpulkan dalam penelitian mereka bahwa transfer of knowledge, baik pada tingkat individu maupun pertukaran pengetahuan secara luas antar organisasi justru berpengaruh negatif terhadap kinerja perusahaan.Namun penelti-peneliti lain menyimpulkan bahwa transfer of knowledge dapat meningkatkan kinerja organisasi (Weldy, 2009; Alipour dan Karimi, 2011; Susanty et.al, 2012; Daniel Palacios-Marques, et.al, 2013).Perbedaan hasil penelitian ini menarik untuk dilakukan pengujian lebih lanjut.

H4: Transfer of Knowledge berpengaruh positif terhadap Kinerja Organisasi.

Selain itu, perlu diperhatikan juga peranan ukuran organisasi (size) sebagai variabel kontrol terhadap kinerja organisasi.Mustikarini dan Fitriasari (2012) dan Hasthoro dan Sunardi (2016) yang menyatakan bahwa ukuran organisasi merupakan prediktor penting yang mempengaruhi kinerja organisasi publik (pemerintah) di Indonesia.

\section{METODE PENELITIAN}

Penelitian ini menggunakan jenis penelitian kuantitatif, dengan menggunakan sumber data primer berupa jawaban kuesioner dari responden yang diperoleh secara online dan data sekunder yang berasal dari inistansi terkait guna mendukung analisis. Responden merupakan pejabat/pegawai Bea Cukai (DJBC) yang bertugas di $103 \mathrm{KPPBC}$ dan 3 KPU BC se-Indonesia sehingga jumlah respon adalah 107 responden yang dianggap mewakili unit-unit organisasi tersebut.

Pengolahan data dan teknik analisis yang digunakan peneltian ini menggunakan metode persamaan struktural (SEM) dengan menggunakan software AMOS 
24.Uji analisis yang diperlukan yakni uji validitas, uji reliabilitas dan uji normalitas datamenggunakan software AMOS 24.

\section{HASIL DAN PEMBAHASAN Proses Pengumpulan Data}

Pengumpulan data dilakukan secara online dari 24 Mei 2018 sampai dengan 01 Juni 2018 dengan response rate 100\%, yaitu sebanyak 107 responden. Profil responden dalam riset ini dapat dilihat sebagaimana pada tabel 2 .

Tabel 2

Profil Responden

\begin{tabular}{lcc}
\hline Keterangan & Jumlah & Presentase (\%) \\
\hline Satuan Kerja & 3 & \\
$\quad$ KPUBC & 104 & 2.8 \\
KPPBC & & 97.2 \\
\hline Pendidikan Terakhir & 23 & \\
$\quad$ Diploma/Akademi & 62 & 21.49 \\
$\quad$ Sarjana/setara & 22 & 57.94 \\
$\quad$ Magister/setara & & \\
\hline Masa Kerja & 20.56 \\
$\quad$ s.d. 9 tahun & 74 & 21.49 \\
10 s.d. 19 tahun & 9 & 69.15 \\
20 s.d. 29 tahun & 1 & 8.41 \\
30 tahun atau lebih & & 0.93 \\
\hline
\end{tabular}

Tabel 3

Uji Validitas dan Reliabilitas

\begin{tabular}{|c|c|c|c|}
\hline Variabel & Indikator & $\begin{array}{c}\text { Hasil } \\
\text { Validitas }\end{array}$ & Hasil Reliabilitas \\
\hline \multirow{6}{*}{$\begin{array}{l}\text { Budaya } \\
\text { Organisasi }\end{array}$} & $\mathrm{B} 01$ & 0.709 & \multirow[t]{6}{*}{0,999} \\
\hline & $\mathrm{BO} 2$ & 0.671 & \\
\hline & $\mathrm{BO} 3$ & 0.819 & \\
\hline & $\mathrm{BO} 4$ & 0.770 & \\
\hline & $\mathrm{B} 05$ & 0.685 & \\
\hline & B06 & 0.838 & \\
\hline \multirow{4}{*}{$\begin{array}{l}\text { Partisipasi } \\
\text { Stakeholder }\end{array}$} & PS1 & 0.846 & \multirow[t]{4}{*}{0,862} \\
\hline & PS2 & 0.732 & \\
\hline & PS3 & 0.814 & \\
\hline & PS4 & 0.726 & \\
\hline \multirow{4}{*}{$\begin{array}{l}\text { Teknologi } \\
\text { Informasi }\end{array}$} & TI1 & 0.808 & \multirow[t]{4}{*}{0,909} \\
\hline & TI2 & 0.900 & \\
\hline & TI3 & 0.817 & \\
\hline & TI4 & 0.851 & \\
\hline \multirow{4}{*}{$\begin{array}{l}\text { Transfer of } \\
\text { Knowledge }\end{array}$} & TK1 & 0.671 & \multirow[t]{4}{*}{0,829} \\
\hline & TK2 & 0.775 & \\
\hline & TK3 & 0.788 & \\
\hline & TK4 & 0.726 & \\
\hline \multirow{4}{*}{$\begin{array}{l}\text { Kinerja } \\
\text { Organisasi }\end{array}$} & K01 & 0.792 & \multirow[t]{4}{*}{0,848} \\
\hline & KO2 & 0.629 & \\
\hline & $\mathrm{KO3}$ & 0.832 & \\
\hline & $\mathrm{KO4}$ & 0.788 & \\
\hline
\end{tabular}

Tabel 2 menjelaskan bahwa karakteristik Sarjana.jika dilihat dari masa kerja, responden secara umum berpendidikan mayoritas responden memiliki masa kerja 
lebih dari 10 tahun sehingga dianggap sudah mengenal dan memahami organisasi tempatnya bekerja.

\section{Uji Validitas dan Uji Reliabilitas}

Suatu indikator dianggap valid jika memiliki nilai standardized loading estimate sebesar 0.50 atau lebih. Sementara menurut Ghozali (2017), nilai kritis reliabilitas suatu data adalah jika nilai contruct reliability setiap variabel sebesar 0.7 atau lebih. Hasil uji validitas dan reliabilitas penelitian ini dapat dilihat pada tabel 3 .

\section{Uji Normalitas Data}

Suatu data dianggap normal jika nilai critical ratio skewness nya berada dalam rentang \pm 2.58 . Berdasarkan hasil penghitungan, data dalam penelitian ini dapat disimpulkan bahwa secara univariate, data terdistribusi normal. Lebih lanjut, pengujian normalitas data dalam penelitian ini dapat dilihat pada tabel 4 .

Tabel 4

Normalitas Data

\begin{tabular}{|l|rrrrrr|}
\hline Variable & min & $\max$ & skew & c.r. & kurtosis & c.r. \\
TK1 & 2.000 & 5.000 & -.544 & -2.297 & .507 & 1.070 \\
TI4 & 2.000 & 5.000 & -.081 & -.341 & -.455 & -.960 \\
KO4 & 3.000 & 5.000 & -.020 & -.083 & -.180 & -.379 \\
PS4 & 2.000 & 5.000 & -.200 & -.843 & -.737 & -1.556 \\
BO6 & 2.000 & 5.000 & -.323 & -1.366 & -.789 & -1.665 \\
BO5 & 2.000 & 5.000 & -.364 & -1.538 & -.388 & -.819 \\
BO4 & 3.000 & 5.000 & .084 & .356 & -1.076 & -2.272 \\
KO3 & 3.000 & 5.000 & .013 & .057 & -.452 & -.953 \\
KO2 & 3.000 & 5.000 & -.051 & -.217 & -.501 & -1.058 \\
KO1 & 3.000 & 5.000 & -.065 & -.275 & -.367 & -.774 \\
TK4 & 2.000 & 5.000 & -.309 & -1.304 & -.083 & -.176 \\
TK3 & 2.000 & 5.000 & -.306 & -1.292 & -.582 & -1.230 \\
TK2 & 2.000 & 5.000 & -.590 & -2.492 & -.080 & -.170 \\
PS1 & 2.000 & 5.000 & -.569 & -2.403 & -.725 & -1.530 \\
PS2 & 3.000 & 5.000 & .044 & .188 & -.616 & -1.300 \\
PS3 & 3.000 & 5.000 & -.431 & -1.819 & -.972 & -2.052 \\
TI1 & 2.000 & 5.000 & -.424 & -1.791 & -.448 & -.947 \\
TI2 & 2.000 & 5.000 & -.230 & -.970 & -.416 & -.879 \\
TI3 & 2.000 & 5.000 & -.325 & -1.372 & -.518 & -1.093 \\
BO3 & 2.000 & 5.000 & -.438 & -1.850 & -.829 & -1.751 \\
BO2 & 2.000 & 5.000 & -.415 & -1.753 & -.565 & -1.194 \\
BO1 & 2.000 & 5.000 & -.602 & -2.544 & .344 & .727 \\
Multivariate & & & & & 20.874 & 3.322 \\
\hline
\end{tabular}

\section{Evaluasi Outliers}

Keberadaan outliers dapat diketahui dengan melihat nilai dari Mahalanobis distance model persamaan tersebut. Tabel 5 adalah hasil output nilai Mahalanobis $d$ squared penelitian ini.

Tabel 5 Output Mahalanobis Distance

Tanpa Variabel Kontrol

Observations farthest from the centroid (Mahalanobis distance) (Group number 1 )

\begin{tabular}{|r|r|r|r}
\hline Observation number & Mahalanobis d-squared & $\mathrm{p} 1$ & $\mathrm{p} 2$ \\
\hline 4 & 44.272 & .003 & .296 \\
33 & 39.025 & .014 & .443 \\
99 & 38.477 & .016 & .251 \\
68 & 36.899 & .024 & .262 \\
2 & 35.858 & .031 & .247
\end{tabular}

Dengan Variabel Kontrol

Observations farthest from the centroid (Mahalanobis distance) (Group number 1)

\begin{tabular}{|r|r|r|r} 
Observation number & Mahalanobis d-squared & $\mathrm{p} 1$ & $\mathrm{p} 2$ \\
\hline 4 & 44.380 & .005 & .398 \\
33 & 41.544 & .010 & .300 \\
99 & 38.531 & .022 & .428 \\
68 & 36.928 & .033 & .474 \\
2 & 36.787 & .034 & .304
\end{tabular}

Nilai cut-off Mahalanobis distance dari penelitian ini adalah 48.26794 (nilai ini diperoleh dengan menggunakan Chi-square pada degree of freedom 22, dengan tingkat signifikansi $\mathrm{p}<0.001$ ). Hal ini mengandung pengertian, jika terdapat hasil output nilai Mahalanobis $d$-squared yang melampaui 48.26794, maka terdapat multivariate outliers.

Berdasarkan tabel 5, model persamaan penelitian ini memiliki nilai output Mahalanobis distance tertinggi 44.272 (model persamaan tanpa variabel kontrol) dan 44.380 (model persamaan dengan variabel kontrol) dan tidak terdapat nilai Mahalanobis yang melebihi 48.26794. Dengan demikian dapat disimpulkan bahwa tidak terdapat outliers pada data penelitian ini.

\section{Uji Confirmatory Factor Analysis (CFA)}

Hasil pengujian CFA menunjukkan bahwa setiap variabel sudah memenuhi kriteria 
goodness of fit sebagaimana dapat dilihat pada nilai setiap indikator Chi-square, CMIN/DF, Probabilitas, GFI, AGFI, TLI, CFI, dan RMSEA masing-masing variable.

\section{Uji Kelayakan Model}

penelitian ini diajukan dua model, dimana model pertama tanpa melibatkan ukuran organisasi sebagai variabel kontrol dan

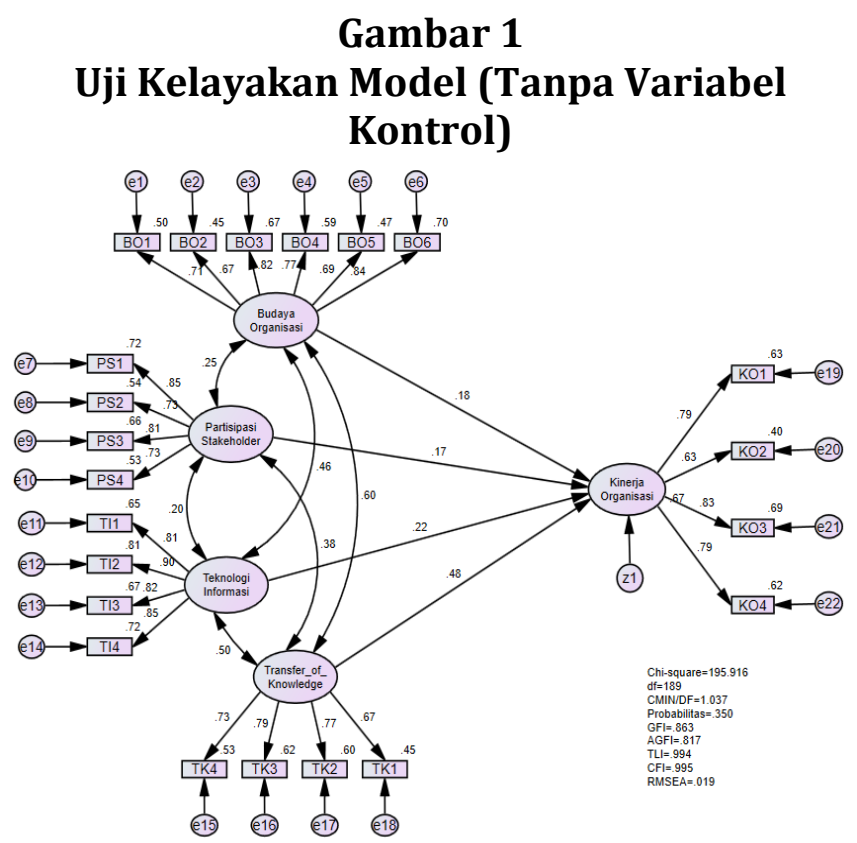

model kedua dengan melibatkan ukuran organisasi sebagai variabel kontrol. Lebih lanjut dapat dilihat sebagaimana Gambar 1 dan 2.

Berdasarkan Gambar 1 dan 2, dapat dilihat bahwa kedua model sudah baik dan memenuhi kriteria Goodness of fit. Tabel 6 menjelaskan ringkasan hasil uji kelayakan model.

\section{Gambar 2 \\ Uji Kelayakan Model (Dengan Variabel Kontrol}

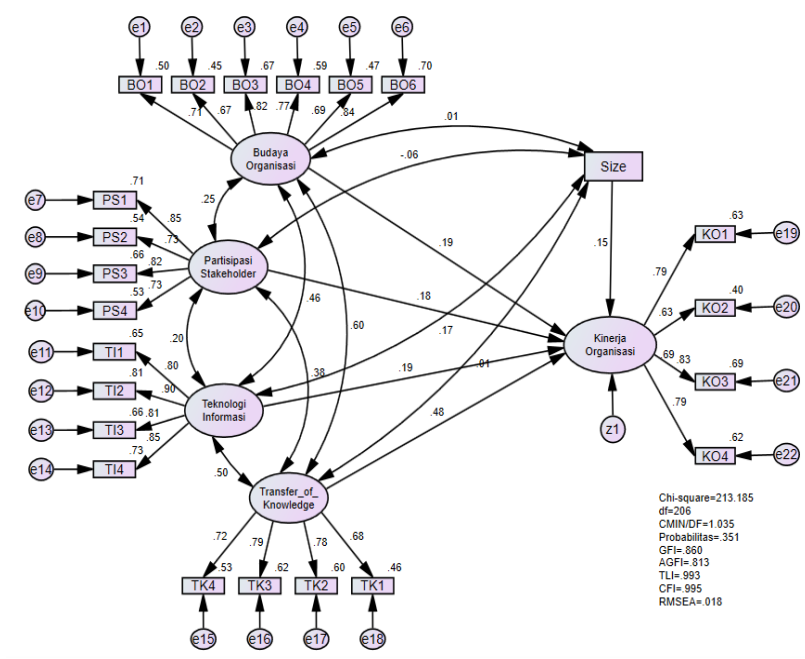

Tabel 6

Haasil Uji Kelayakan Full Model

\begin{tabular}{|c|c|c|c|c|c|}
\hline \multirow[b]{2}{*}{ No } & \multirow[b]{2}{*}{ Fit Index } & \multirow[b]{2}{*}{ Cut Off Value } & \multicolumn{2}{|c|}{ Hasil Analisis } & \multirow[b]{2}{*}{ Evaluasi } \\
\hline & & & tanpa Size & dengan Size & \\
\hline 1 & Chi-Square & $\begin{array}{c}\text { tanpa VC: }<222.0756 \\
\text { (df:189; } \alpha=5 \%) \\
\text { dengan VC: }<240.4847 \\
\text { (df:206; } \alpha=5 \%)\end{array}$ & 195.916 & 213.185 & Fit \\
\hline 2 & Probabilitas & $\geq 0.05$ & 0.350 & 0.351 & Fit \\
\hline 3 & CMIN/DF & $\leq 2.00$ & 1.037 & 1.035 & Fit \\
\hline 4 & RMSEA & $\geq 0.90$ & 0.863 & 0.860 & Marjinal \\
\hline 5 & GFI & $\geq 0.90$ & 0.817 & 0.813 & Marjinal \\
\hline 6 & AGFI & $\geq 0.90$ & 0.994 & 0.993 & Marjinal \\
\hline 7 & TLI & $\geq 0.95$ & 0.995 & 0.995 & Fit \\
\hline 8 & CMIN/DF & $\leq 0.08$ & 0.019 & 0.018 & Fit \\
\hline
\end{tabular}


Tabel 7

Kesimpulan Hipotesis Penelitian

\begin{tabular}{|c|c|c|c|c|c|c|c|}
\hline \multirow[t]{2}{*}{ Hipotesis Penelitian } & \multicolumn{3}{|c|}{ tanpa Size } & \multicolumn{3}{|c|}{ dengan Size } & \multirow[t]{2}{*}{ Kesimpulan } \\
\hline & est. & C.R. & $\mathrm{P}$ & est. & C.R. & $\mathrm{P}$ & \\
\hline $\begin{array}{l}\text { H1: Budaya Organisasi } \\
\text { berpengaruh positif terhadap } \\
\text { Kinerja Organisasi }\end{array}$ & 0.127 & 1.689 & 0.091 & 0.135 & 1.792 & 0.073 & $\begin{array}{l}\text { Diterima pada } \\
\alpha=10 \%\end{array}$ \\
\hline $\begin{array}{l}\text { H2: Partisipasi Stakeholder } \\
\text { berpengaruh positif terhadap } \\
\text { Kinerja Organisasi }\end{array}$ & 0.170 & 2.009 & 0.045 & 0.177 & 2.169 & 0.030 & $\begin{array}{l}\text { Diterima pada } \\
\alpha=5 \%\end{array}$ \\
\hline $\begin{array}{l}\text { H3: Teknologi Informasi } \\
\text { berpengaruh positif terhadap } \\
\text { Kinerja Organisasi }\end{array}$ & 0.451 & 2.343 & 0.019 & 0.457 & 1.995 & 0.046 & $\begin{array}{l}\text { Diterima pada } \\
\alpha=5 \%\end{array}$ \\
\hline $\begin{array}{l}\text { H4: Transfer of Knowledge } \\
\text { berpengaruh positif terhadap } \\
\text { Kinerja Organisasi }\end{array}$ & 0.166 & 3.648 & $* * *$ & 0.142 & 3.728 & $* * *$ & $\begin{array}{l}\text { Diterima pada } \\
\alpha=5 \%\end{array}$ \\
\hline Size (ukuran organisasi) sebag & label & trol & & 0.044 & 2.062 & 0.039 & diterima $\alpha=5 \%$ \\
\hline
\end{tabular}

Berdasarkan Tabel 7, berikut pembahasan atas hasil analisis SEM dari penelitian ini. (1) Pada hubungan antara variabel budaya organisasiterhadap kinerja organisasi,nilai critical ratio positif sebesar 1.689 dan 1.792. Selanjutnya nilai $p$-value 0.091 dan 0.073 berada di atas 0.05 , namun masih berada di bawah 0.10 . Oleh sebab itu, dapat disimpulkan bahwa budaya organisasi berpengaruh positif dan signifikan terhadap kinerja organisasi pada $\alpha=10 \%$; (2) Pada hubungan Partisipasi Stakeholder terhadap Kinerja Organisasidapat dilihat nilai p-value sebesar 0.045 dan 0.030 . Selanjutnya, nilai critical ratio sebesar positif 2.009 dan 2.169.Hal ini menunjukkan bahwa partisipasi stakeholder berpengaruh positif dan signifikan terhadap kinerja organisasi; (3) Pada hubungan teknologi informasi terhadap kinerja organisasidapat dilihat nilaicritical ratio sebesar 2.343, meskipun ketika melibatkan ukuran organisasi sebagai variable control mengalami penurunan nilai critical ratio menjadi 1.995 . Selanjutnya nilai $p$-value0.019 dan 0.046.0leh sebab itu, dapat disimpulkan bahwa teknologi informasi berpengaruh positif dan signifikan terhadap kinerja organisasi; (4) Pada hubungan transfer of knowledge terhadap kinerja organisasi dapat dilihat nilai critical ratio sebesar 3.648 dan 3.728. Selanjutnya nilai $p$-value yang mendekati nol $\left(^{* * *}\right)$.Dengan demikian, dapat disimpulkan bahwa transfer of knowledge berpengaruh signifikan terhadap kinerja organisas; (5) Ukuran organisasi (size) sebagai variabel control merupakan faktor penting terhadap kinerja organisasi dengan signifikansi 0.039, sehingga disimpulkan bahwa ukuran organisasi memiliki pengaruh positif terhadap kinerja organisasi.

\section{KESIMPULAN DAN SARAN}

Dari hasil penelitian, terdapat implikasi yang dapat diperhatikan oleh para pimpinan organisasi di Direktorat Jenderal Bea dan Cukai sebagaimana tabel 8. 


\section{Tabel 8}

\section{Implikasi Manajerial}

\begin{tabular}{|c|c|c|}
\hline No. & Fokus & Implikasi Manajerial \\
\hline 1. & $\begin{array}{l}\text { Transfer of } \\
\text { Knowledge }\end{array}$ & $\begin{array}{l}\text { a. Perlu adanya program pendidikan dan pelatihan yang sesuai } \\
\text { dengan kebutuhan organisasi terhadap para pegawai yang } \\
\text { dilakukan secara rutin. } \\
\text { b. Membiasakan komunikasi yang efektif antar pegawai sehingga } \\
\text { para pegawai dapat berbagi ilmu pengetahuan yang bermanfaat } \\
\text { dalam menjalankan tugasnya. } \\
\text { c. Mendorong peningkatan kerja sama antar pegawai (teamwork). } \\
\text { d. Monitoring dan asistensi terhadap implementasi pengetahuan para } \\
\text { pegawai pada pekerjaan mereka. }\end{array}$ \\
\hline 2. & Teknologi Informasi & $\begin{array}{l}\text { a. Setiap unit organisasi hendaknya tersedia perangkat teknologi } \\
\text { informasi yang sesuai dengan perkembangan zaman dan beban } \\
\text { kerja organisasi. } \\
\text { b. Penggunaan teknologi informasi yang sesuai dengan peruntukan } \\
\text { (TI dipergunakan hanya untuk menyelesaikan tugas-tugas } \\
\text { organisasi) } \\
\text { c. Akses teknologi informasi yang memudahkan bagi pegawai dalam } \\
\text { menyelesaikan tugasnya. } \\
\text { d. Ketersediaan tenaga ahli teknologi informasi guna menjaga agar } \\
\text { teknologi informasi berfungsi optimal. }\end{array}$ \\
\hline 3. & $\begin{array}{l}\text { Partisipasi } \\
\text { Stakeholder }\end{array}$ & $\begin{array}{l}\text { a. Perlu peranan instansi terkait (seperti DPR, Kementerian } \\
\text { Keuangan) serta para pengguna jasa dalam tahapan analisis } \\
\text { kebutuhan/inisiasi. } \\
\text { b. Peranan instansi terkait dalam menyusun tujuan organisasi, } \\
\text { termasuk dalam menentukan target kinerja organisasi agar sejalan } \\
\text { dengan tujuan nasional. } \\
\text { c. Perlu adanya supervisi dari instansi terkait (seperti Kementerian } \\
\text { Keuangan) dalam mengimplementasikan program-program } \\
\text { organisasi. } \\
\text { d. Peranan instansi pengawas (seperti inspektorat, BPK) dalam tahap } \\
\text { evaluasi serta para stakeholder (survey kepuasan pengguna jasa). }\end{array}$ \\
\hline 4. & Budaya Organisasi & $\begin{array}{l}\text { a. Mendorong tumbuhnya integritas, sinergi, melayani publik secara } \\
\text { proporsional dan professional. (mengejawantahkan nilai-nilai } \\
\text { Kementerian Keuangan). } \\
\text { b. Memperhatikan keterlibatan pegawai dalam pelaksanaan tugas } \\
\text { organisasi. } \\
\text { c. Mendorong pola komunikasi yang efektif dalam organisasi. } \\
\text { d. Memperhatikan reward system yang adil dan konsisten terhadap } \\
\text { para pegawai. } \\
\text { e. Penguatan lingkungan pengendalian internal. } \\
\text { f. Mendorong dan membantu para pegawai dalam memahami tujuan } \\
\text { organisasi. }\end{array}$ \\
\hline
\end{tabular}

\section{Keterbatasan Penelitian}

Penggunaan metode kuesioner secara online di satu sisi dapat memberi kemudahan akses dalam penyebaran oleh penulis dan cakupan responden yang luas. Di sisi lain, penelitian ini memiliki beberapa keterbatasan sebagai berikut:

1. Kesulitan untuk melakukan konfirmasi ulang atas jawaban-jawaban responden karena sangat tergantung dengan kesediaan responden dikarenakan 
penulis tidak bertatap muka secara langsung.

2. Bagi responden yang mengalami keterbatasan akses terhadap teknologi informasi akan mengalami kesulitan dalam memberikan respon.

3. Kesulitan dalam memastikan semua kuesioner benar-benar diisi oleh semua responden yang bersangkutan atau tidak.

\section{Agenda Penelitian Mendatang}

Pada agenda penelitian yang akan data yang diharapkan oleh peneliti adalah sebagai berikut:
1. Penelitian mendatang disarankan untuk mengambil obyek yang berbeda, tetapi masih di lingkungan organisasi publik atau pemerintahan.

2. Riset mendatang hendaknya menambahkan beberapa variabel, seperti efektifitas pengukuran kinerja organisasi, pembelajaran organisasi (learning organization), kemampuan beradaptasi, knowledge management.

\section{REFERENSI}

Adams, G. B., and Balfour, D. L. 2009. Unmasking Administrative Evil.(3rd edition) Thousand Oaks, Calif.: Sage.

Alipour, F., Karimi, R. 2011."Mediation Role of Innovation and Knowledge Transfer in the Relationship between Learning organisation and Organisational Performance".International Journal of Business and Social Science Vol.2 No.19, pp. 144147.

Amin, M. A. M. 2010. "Measuring the performance of Customs Information Systems (CIS) in Malaysia".World Customs Journal. Vol.4 No.2, pp. 89-104.

Argote L, Ingram P. 2000. "Knowledge transfer: a basis for competitive advantage in firms." Organisational Behaviour and Human Decision Processes. Vol.82 No.1, pp. 150-169.

Atkinson, Helen. 2006. "Strategy Implementation: A Role for The Balanced Scorecard?".Management Decision, Vol. 44 No. 10, pp. 1441-1460.

Bose, R. 2009. "Advanced analytics: opportunities and challenges".Industrial Management \& Data Systems, Vol. 109(2), pp. 155-172.

Bobrova, Anna V. 2016. "Assessment of the performance of Russian customs authorities".World Customs Journal, Vol. 11 No.2, pp. 37-48.

Bresman, H., Birkinshaw, J.M., \& Nobel, R. 2010. "Knowledge transfer in international acquisitions: a retrospective". Journal of International Business Studies, Vol. 41, 21-26. doi:10.1057/jibs.2009.71.

Chen, Ssu-Hsien. 2017. "Who Cares: Stakeholder Participation and the Use of Performance Information in Strategic Planning". Chinese Public Administration Review. Vol. 8 issue 2, pg. 86-103.

Chong, S. C., Salleh, K., Ahmad, S.N.S. and Sharifuddin, S.S.O. (2011). "KM implementation in a public sector accounting organisation: an empirical investigation". Journal of Knowledge Management, Vol. 15(3), pg. 497-512.

Chowdhury, A. 2003. "Information technology and productivity payoff in the banking industry: 
Evidence from the emerging market". Journal of International Development. Vol 15, pp. 693-708.

Dedrick, J, V. Gurbaxani, and K.L. Kraemer. 2003. "Information Technology and Economic Performance: A Critical Review of the Empirical Evidence”.ACM Computing Surveys, Vol. 35, No. 1, pp. 1-28.

Devaraj, S., and Kohli, R. 2000. "Information technology payoff in the health-care industry: A longitudinal study". Journal of Management Information Systems, Vol. 16, pp. 41-67.

DJBC.2018. Laporan Kinerja Direktorat Jenderal Bea dan Cukai Tahun Anggaran 2017.Kementerian Keuangan Republik Indonesia.

-----. 2017. Laporan Kinerja Direktorat Jenderal Bea dan Cukai Tahun Anggaran 2016.Kementerian Keuangan Republik Indonesia.

-----. 2016. Laporan Kinerja Direktorat Jenderal Bea dan Cukai Tahun Anggaran 2015.Kementerian Keuangan Republik Indonesia.

-----. 2015. Laporan Kinerja Direktorat Jenderal Bea dan Cukai Tahun Anggaran 2014.Kementerian Keuangan Republik Indonesia.

Djokosantoso, Moeljono. 2003. Budaya Korporat dan Keunggulan Korporasi. Elex Media Komputindo: Jakarta.

Duan Y, Nie W, Coakes E. "Identifying key factors affecting transnational knowledge transfer". Information \& Management.Vol. 47, pp.356-363.

Federal Board of Revenue. 2015. "Key Performance Indicators \& Job Description of Customs Officers (Field Formations)". Federal Board of Revenue: Pakistan.

Ghozali, Imam. 2017. Model Persamaan Struktural Konsep dan Aplikasi Dengan Program AMOS 24 Update Bayesian SEM Edisi 7. Badan Penerbit Undip: Semarang.

Gupta, A.K. and Govindarajan, Vijay. 2000. "Knowledge flows within multinational corporations". Strategic Management Journal, Vol. 21, pp. 473-496.

Gwardzinska, Ewa. 2012. "The standardisation of customs services in the European Union". World Customs Journal, Vol. 6 No.1, pp. 93-100.

Hajidimitriou, Y.A., Sklavounos, N.S., Rotsios K.P. 2012. "The impact of trust on knowledge transfer in international business systems". Scientific Bulletin - Economic Sciences, Vol. 11/ Issue 2, pg. 39-49.

Hakanson, L. and Nobel, R. 2000. "Technology Characteristics and Reverse Technology Transfer". Management International Review, Vol. 40, No. 1, International Management of Technology: Theory, Evidence and Policy, pg. 29-48.

Hasthoro, H.A. and Sunardi. 2016. "Tata Kelola Publik dan Kinerja Keuangan Pemerintah Daerah di Indonesia". Jurnal Ekonomi dan Bisnis, Volume XIX No. 1, pg. 53-68.

Indonesia Corruption Watch.2005. Instansi Paling Korup.https://antikorupsi.org/ id/news/instansi-paling-korup.diakses pada 21 Maret 2018.

Ismail, Anita dan Mamat, Mazlina. 2012. "The Relationship Between Information Technology, Process Innovation and Organisational Performance". International Journal of Business and Social Science. Vol.3 No.2, pg. 268-274.

Juwita, R, Mutimmatul Adzkhiyah. 2017. "Internal Control and Organisational Culture in the Improvement of Managerial Performance".Trikonomika Volume 16, No. 2, December 2017, pg. 68-74.

Keban, J.T. 2003.Indikator Kinerja Pemerintah Daerah: Pendekatan Manajemen dan Kebijakan. 
Makalah,Seminar Sehari. Fisipol UGM. Yogyakarta.

Lai, K.H., Ngai, E.W.T., and Cheng, T.C.E. 2005.“Information technology adoption in Hong Kong's logistics industry".Transportation Journal, Vol. 44, pg.1-9.

Levine, S.S., M.J. Prietula, (2012) "How Knowledge Transfer Impacts Performance: A Multilevel Model of Benefits and Liabilities". Organisation Science vol. 23(6):1748-1766.

Lumanaj, Jasmina. 2015. "Albanian Customs Service: Quality of Services and Performance of Albanian Customs Administration". International Journal of Economics, Commerce and Management United Kingdom. Vol. 3 Issue 10, pp. 548-558.

Mangkunegara, A.A. Anwar Prabu. 2010. Evaluasi Kinerja SDM, Bandung: PT Revika Aditama.

Matsuda, Shingo. 2012. "The Time Release Study as a performance measurement tool for a supply chain and an international corridor". World Customs Journal, Vol. 6 No.1, pp. 7992.

Mlanya, L.M. 2015.Stakeholder Involvement in Strategic Management and Performance of British-American Investments Company Limited (BAICL).University of Nairobi.Thesis.

Morikawa, M. 2004. "Information Technology and the Performance of Japanese SMEs".Small Business Economics, Vol.23: pg.171-177.

Mustikarini, W. A., dan D. Fitriasari. 2012. "Pengaruh Karakteristik Pemerintah Daerah dan Temuan Audit BPK Terhadap Kinerja Pemerintah Daerah Kabupaten/Kota di Indonesia Tahun Anggaran 2007". Proceeding Simposium Nasional Akuntansi XV Banjarmasin, pg.122.

Muthuveloo, R., N. Shanmugam, Ai Ping Teoh. 2017. "The impact of tacit knowledge management on organisational performance: Evidence from Malaysia". Asia Pacific Management Review, Vol. 22, pg. 192-201.

Nyandika, O. F \& Ngugi, K. 2014."Influence of Stakeholders' Participation on Performance of Road Projects at Kenya National Highways Authority”.European Journal of Business Management, Vol.1 (11), pg. 384-404.

O’Brien, J. A \& Marakas, G. M. 2010. Introduction to Information Systems, Fifteenth Edition. McGraw-Hill Companies, Inc: New York.

Palacios-Marqués, D., Marta P., José M.M., (2013) "The effect of knowledge transfer on firm performance: An empirical study in knowledge-intensive industries", Management Decision, Vol. 51 Issue: 5, pp.973-985.

Pangewa, M. 2015. "The Influence of the Organisational Culture toward the Performance of Local Governance”.Mediterranean Journal of Social Sciences, vol. 6 no. 6 S4, pp. 307-314.

Peslak, A.R. 2003. "A firm level study of information technology productivity using financial and market-based measures". Journal of Computer Information Systems, Vol. 43, pg. 7281.

Peteraf, M. 1993. "The cornerstones of competitive advantage: A resource-based view". Strategic Management Journal, Vol. 14(3), pg. 179-191.

Prawirosentono, S. 2008. Manajemen Sumber Daya Manusia "Kebijakan Kinerja Karyawan". Yogyakarta: BPFE.

Puspitasari, D.D., Sutopo, Enny I. 2016. "Pengaruh Budaya Organisasi, Pelatihan, dan Komunikasi terhadap kinerja karyawan pada PT KAI (Persero) Tbk". Jurnal Manajemen BRANCHMARCK. Vol.2 issue 2, pg. 89-101.

'Rainey, Hal G. 2010. Understanding and Managing Public Organisations $4^{\text {th }}$ Edition.Josey-Bass 
A Wiley Imprint.

Rosenblatt, V. 2011.The impact of institutional processes, social networks, and culture on diffusion of global work values in multinational organisations".Cross Cultural Management: An International Journal, Vol.18(1), pg. 105-121. doi: 10.1108/13527601111104322

Sarosa, Samiaji and Didar Zowghi. 2003. "Strategy for Adopting Information Technology for SMEs: Experience in Adopting Email within an Indonesian Furniture Company". Electronic Journal of Information Systems Evaluation, Volume 6 Issue 2, pp.165-176.

Schein, E.H. 2004.Organisational Culture and Leadership $3^{\text {rd }}$ edition. Jossey-Bass: San Francisco.

Susanty, A, Naniek U.H., Mahardian Y.H. 2012. "Key Success Factors that Influence Knowledge Transfer Effectiveness: A Case Study of Garment Sentra at Kabupaten Sragen". Procedia Economics and Finance 4, pp. 23 - 32.

Taylor, Jeannette. 2014. "Organisational Culture and the paradox of Performance Management". Public performance \& Management Reviewer, vol 38 issue 1, pg. 7-22.

Testa, M. R. \& Sipe, L. J. 2013. “The Organisational Culture Audit: Countering Cultural Ambiguity in the Service Context". Open Journal of Leadership, Vol.2(02), pg. 36-44.

William, A.D. 2014. "Effectiveness of Performance Management Systems in State Agencies: Performance Measurement, Organisational Culture and Learning". University of Colorado.Dissertation.

Weldy, T.G. 2009."Learning organisation and transfer: strategies for improving performance". The Learning Organisation, Vol. 16 Issue: 1, pp.58-68.

Yang, K and J.Y. Hsieh. 2007. "Managerial Effectiveness of Government Performance Measurement: Testing a Middle-Range Model". Public Administration ReviewVol.67(5), pg. 861-879. 